\title{
UNIFORM LIGHT SOURCE WITH INTENSITY CONTROL USING
}

\section{LEDs}

\author{
Shubha Kulkarni ${ }^{1}$, Ramamani $V^{2}$, K Rajaram ${ }^{3}$, Manjunatha Babu $\mathbf{P}^{4}$ \\ ${ }^{1}$ Assistant Professor, EEE Department, DSCE, Bangalore, \\ smk.1978@gmail.com \\ ${ }^{2}$ Assistant Professor, EEE Department, DSCE, Bangalore \\ ${ }^{3}$ Assistant Professor, EEE Department, DSCE, Bangalore \\ ${ }^{4}$ Assistant Professor, EEE Department, BMSIT\&M, Bangalore \\ manjubabup@gmail.com
}

\begin{abstract}
The main objective of this paper is to reduce the size and the power consumption of the backlight unit. This was realized by intensity control of LEDs, as dimming of LEDs saves power. The information display devices play a major role in the transition to information oriented societies. The global move toward information societies is causing a sharp increase in the demand for information display devices. The rapid development of light emitting diodes (LEDs) over the past few years has surpassed the characteristics of incandescent lamps in luminous efficiency, durability, reliability, safety and power requirements. Though modern high power LEDs which produces up to $120 \mathrm{~lm}$ per device, several individual LEDs must be mounted on panels to obtain practical power. Nevertheless, in many lighting application a uniform illumination distribution is desired, which is affected by both the packing density and the array configuration of LEDs.
\end{abstract}

Keywords: $L C D, L E D, C R T, T L C$

\section{INTRODUCTION}

A backlight is a form of illumination used in liquid crystal displays [1]. As LCDs do not produce light themselves, they need illumination to produce a visible image. Backlights illuminate the LCD from the side or back of the display panel, unlike front lights, which are placed in front of the LCD [2]. Backlights are used in small displays to increase readability in low light conditions, and in computer displays and LCD televisions to produce light in a manner similar to a CRT display. Simple types of LCD displays are built without an internal light source, requiring external light sources to convey the display image to the user. Modern LCD screens, however, are built with an internal light source. Such LCD screens consist of several layers [3-6]. The backlight is usually the first layer from the back. The backlight circuit consumes almost $70-80 \%$ of the total circuit power. Reduction in backlight power is the one of the main concerns in today's technology. CFL's that are mostly used as backlight for LCD screens have many disadvantages and short life.

\section{MODEL AND DESIGN}

DRIVER MODULE
$* * *$

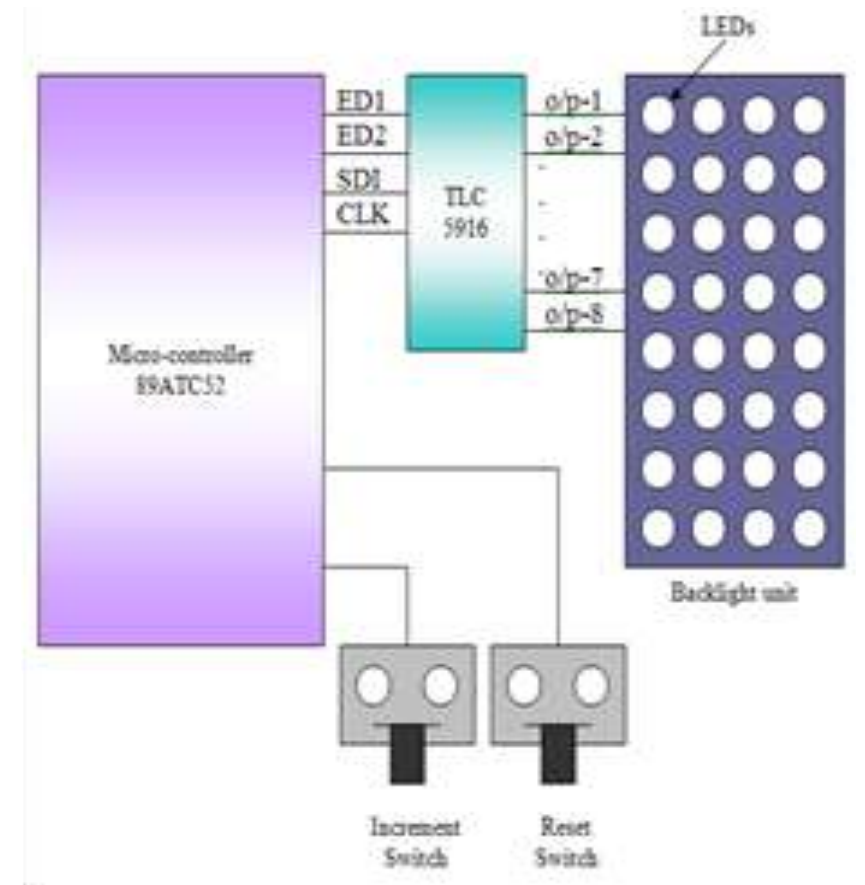

The Micro-Controller 80ATC52 enables all the output pins of the TLC 5916 IC. Then micro controller initializes the backlight unit to half brightness, there are two interrupts which are enabled, one for incrementing the brightness and other to reset the backlight intensity to 20 . When the increment interrupt is activated the next 8-bit intensity code is sent and is latched. In order to set the current gain 
according to the 8-bit code the TLC IC must be shifted to special mode. Thus the micro-controller shifts the TLC from normal mode to special mode by generating control signals. Again in order to set the new current value to the output pins, the TLC must be brought back to normal mode.

\section{Backlight Module}

\section{a) Square Array}

Design of Square LED Array backlight. The LEDs are placed in Square arrangement separated by a distance of $8 \mathrm{~mm}$ pitch (centre to centre). The illumination pattern was observed at different heights of the screen. The uniform illumination was observed at greater distance of the screen from the LEDs. As the distance of the screen increases the uniformity is better.

\section{b) Staggered Array}

Design of staggered LED Array backlight. The LEDs are placed in Square arrangement separated by a distance of $8 \mathrm{~mm}$ pitch (centre to centre). The alternate rows are shifted by a distance $\mathrm{D} / 2$. The illumination pattern was observed at different heights of the screen. The uniform illumination was observed at greater distance of the screen from the LEDs. As the distance of the screen increases the uniformity is better.

\section{Edge Lighting Modules}

\section{a) Single Side Tapered Lightguide}

Acrylic plate of $5 \mathrm{~mm}$ thickness is used as light guide. First the lightguide was tapered at an angle, one edge having the thickness $5 \mathrm{~mm}$ and the other $2 \mathrm{~mm}$. Triangular grooves were made on the tapered side of the light guide to project the light upwards. The dimension of the grooves base is $5 \mathrm{~mm}$ and the height is $1 \mathrm{~mm}$. It forms a right angled triangle. The LEDs are mounted on the thicker edge and single side edge lighting is observed.

\section{b) Double Side Tapered Lightguide}

Acrylic plate of $5 \mathrm{~mm}$ thickness is used as light guide. First the lightguide was tapered at an angle from both the edges. The edge having the thickness $5 \mathrm{~mm}$ and at the centre the thickness is $2 \mathrm{~mm}$. Triangular grooves were made on the tapered side of the light guide to project the light upwards. The dimension of the grooves base is $5 \mathrm{~mm}$ and the height is $1 \mathrm{~mm}$. it forms a right angled triangle. The LEDs are mounted on both the edges and double side edge lighting is observed.

\section{c) V-Groove Lightguide}

Acrylic plate of $5 \mathrm{~mm}$ thickness is used as light guide. Triangular grooves were made on one side of the light guide. The dimension of the grooves is, the base is $5 \mathrm{~mm}$ and the height is $1 \mathrm{~mm}$. The grooves a made in the form of isosceles triangle. The LEDs are mounted on the edge of VGrooves on both the sides and the illumination pattern was observed.

Similarly one more module of V-grooves was made by differing the size of the grooves. The dimension of this $\mathrm{V}$ -
Groove module is the base is $1 \mathrm{~mm}$ and the height of the VGroove is $1 \mathrm{~mm}$. The numbers of grooves in this module are more. A better illumination pattern was observed.

\section{d) Laser Etched Lightguide}

Acrylic plate of $10 \mathrm{~mm}$ thickness is used as lightguide. The grooves were made by laser etching. It is similar to printed light extraction technique. The intensity of the grooves at the centre is more and gradually decreases at the edges. This is to have uniform illumination on all points of the surface of the lightguide plate. When the plate is edge lit most of the light is projected upwards at the edges only and only partial light is available at the centre in other modules. In this module the light is extracted uniformly at all points. A better illumination pattern was observed in this module.

\section{e) Light Box}

We made a small prototype of a light box, the bottom and side surface is a normal mirror. The top surface is a partial mirror which reflects $55 \%$ of the light, $22 \%$ of the light is transmitted and remaining is losses incurred. The light from one side is reflected back and forth (causing multiple reflection) in the gap between the top and bottom surfaces. Hence the light illuminates the top surface uniformly. The main criterion is the angle of launching of the light into the light box.

\section{SIMULATION AND ANALYSIS}

\section{Square Array}
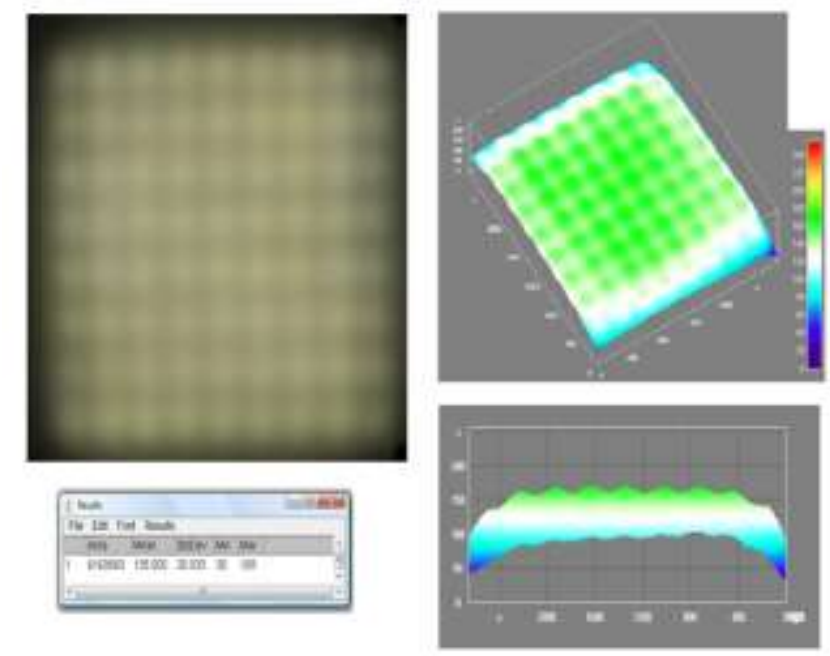


\section{Staggered Array}
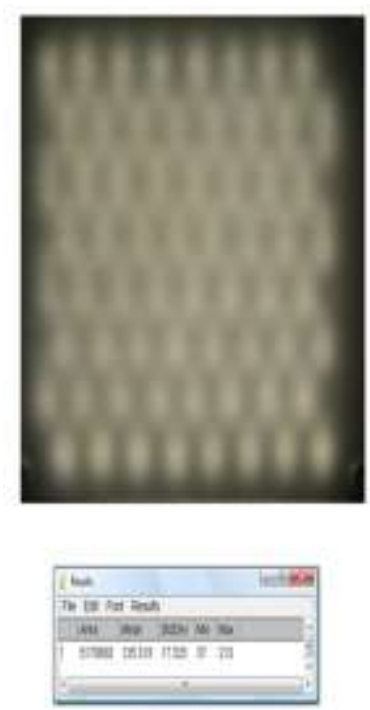

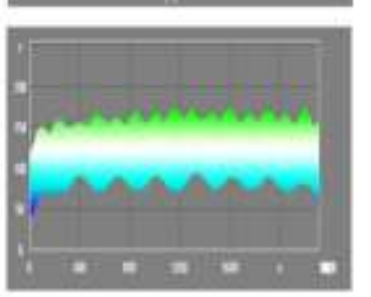

\section{Single Side Tapered Lightguide}

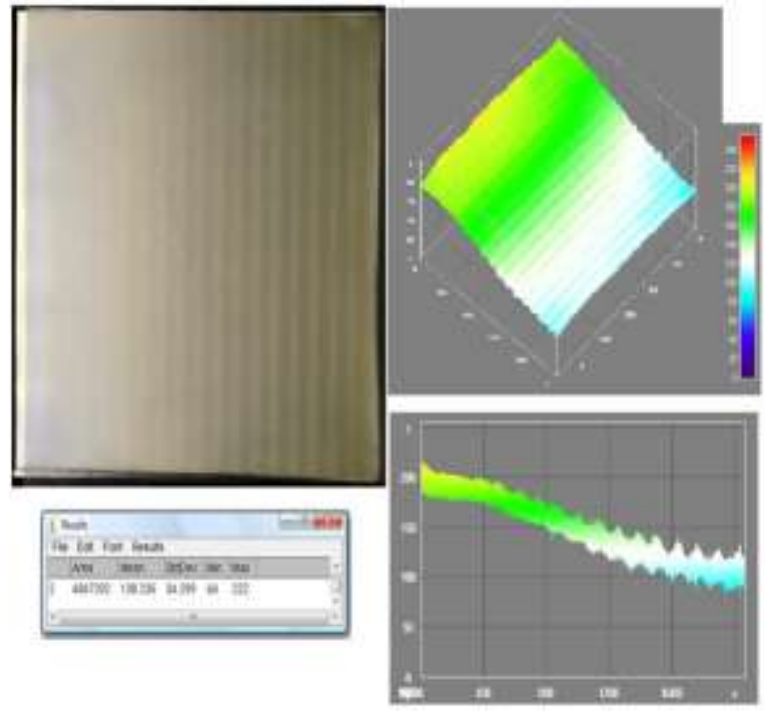

\section{Double Side Tapered Lightguide}

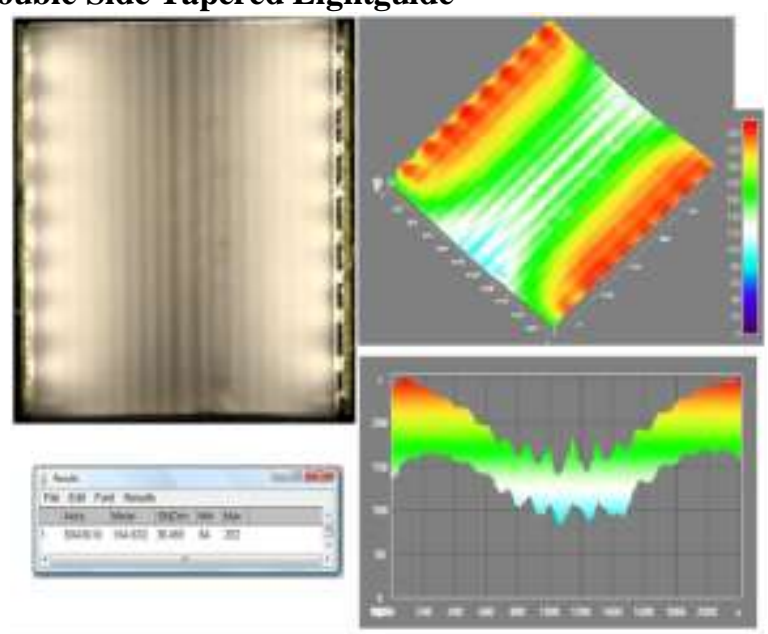

\section{V-Groove Lightguide}
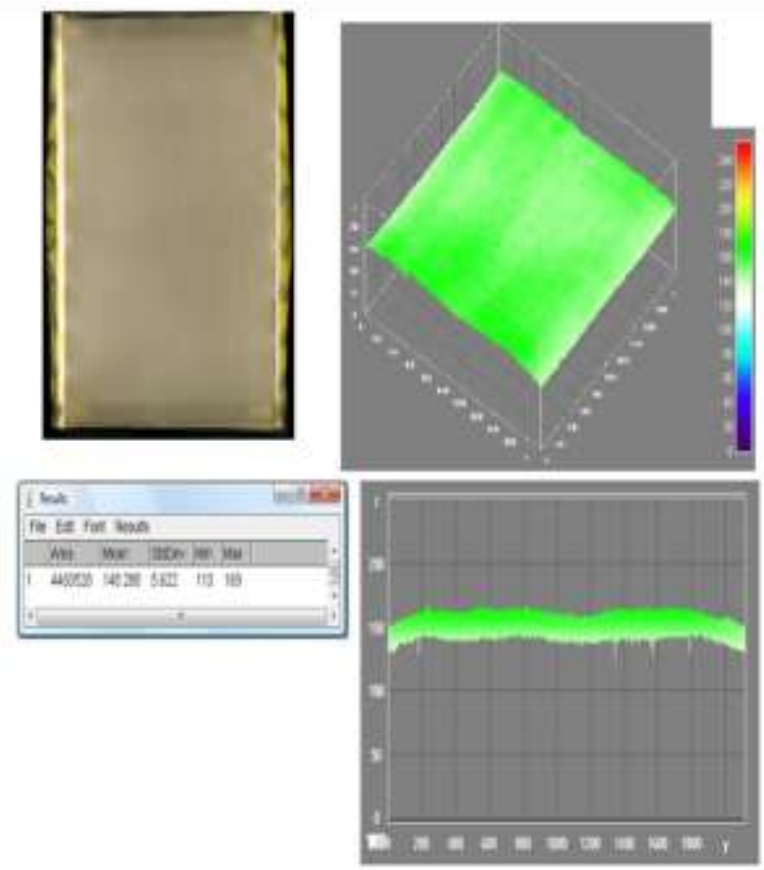

\section{Laser Etched Lightguide}

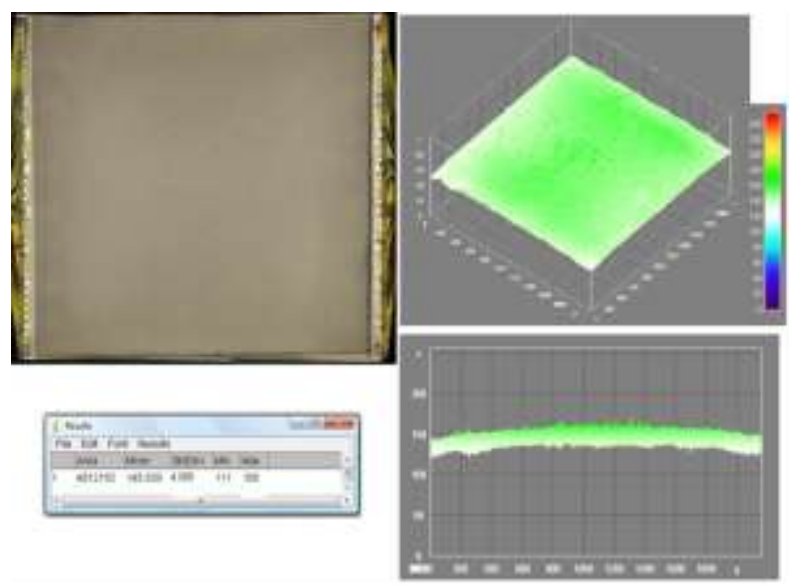

Light Box

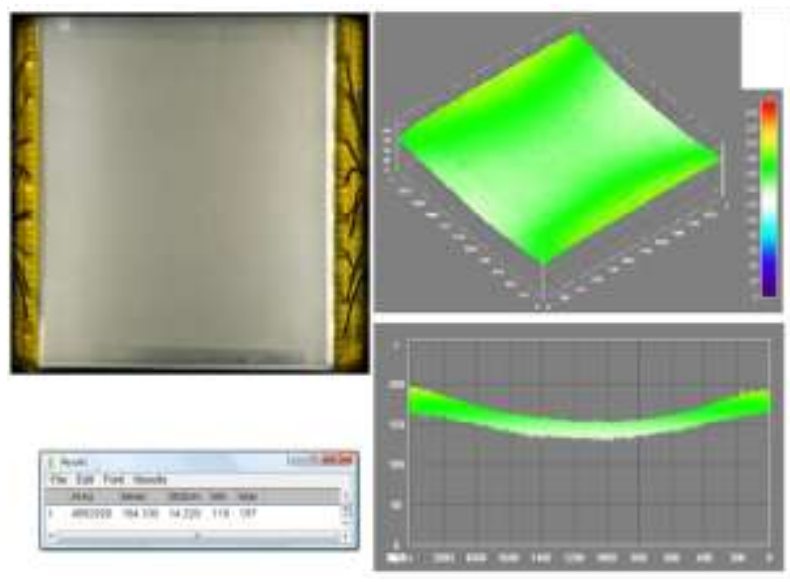




\section{RESULTS}

\begin{tabular}{|c|c|c|c|c|c|}
\hline \multirow{2}{*}{\multicolumn{2}{|c|}{ Lightguide }} & \multicolumn{4}{|c|}{ Practical values } \\
\hline & & Mean & $\begin{array}{l}\text { Std } \\
\text { Dev }\end{array}$ & Min & Max \\
\hline \multirow{3}{*}{ Square } & $\begin{array}{l}5 \mathrm{~mm} \\
\text { height }\end{array}$ & 125.2 & 26.5 & 28 & 226 \\
\hline & $\begin{array}{l}10 \mathrm{~mm} \\
\text { height }\end{array}$ & 135 & 20 & 30 & 199 \\
\hline & $\begin{array}{l}15 \mathrm{~mm} \\
\text { height }\end{array}$ & 123.5 & 17.7 & 38 & 192 \\
\hline \multirow{3}{*}{ Staggered } & $\begin{array}{l}5 \mathrm{~mm} \\
\text { height }\end{array}$ & 133.8 & 31.7 & 15 & 223 \\
\hline & $\begin{array}{l}10 \mathrm{~mm} \\
\text { height }\end{array}$ & 135.3 & 17.3 & 37 & 213 \\
\hline & $\begin{array}{l}15 \mathrm{~mm} \\
\text { height }\end{array}$ & 135.6 & 11.3 & 80 & 199 \\
\hline $\begin{array}{l}\text { Single side } \\
\text { taper }\end{array}$ & $\begin{array}{c}\text { VIII } \\
\text { intensity }\end{array}$ & 138.2 & 34.2 & 64 & 222 \\
\hline $\begin{array}{l}\text { Double side } \\
\text { tapered }\end{array}$ & $\begin{array}{c}\text { VIII } \\
\text { intensity }\end{array}$ & 164.6 & 36.4 & 84 & 252 \\
\hline \multirow{3}{*}{ V grooves } & $\begin{array}{c}5 \mathrm{~mm} \\
\text { width, } \\
\text { VIII } \\
\text { intensity }\end{array}$ & 148.2 & 5.6 & 113 & 169 \\
\hline & $\begin{array}{c}1 \mathrm{~mm} \\
\text { width, }\end{array}$ & \multirow{2}{*}{156.7} & \multirow{2}{*}{9} & \multirow{2}{*}{128} & \multirow{2}{*}{187} \\
\hline & $\begin{array}{c}\text { VIII } \\
\text { intensity }\end{array}$ & & & & \\
\hline $\begin{array}{l}\text { Laser } \\
\text { etched }\end{array}$ & $\begin{array}{c}\text { VIII } \\
\text { intensity }\end{array}$ & 145 & 4.5 & 111 & 159 \\
\hline Light box & $\begin{array}{c}\text { VIII } \\
\text { intensity }\end{array}$ & 154.1 & 14.2 & 119 & 197 \\
\hline
\end{tabular}

All the above values are measured in intensity per pixel. The image resolution is $10 \mathrm{M}$ pixel.

\section{CONCLUSION}

All the modules required to build a uniform illuminating surface namely square array, staggered array, single side tapered light guide, double side tapered light guide, VGroove light guide, laser etched light guide and light box module have been successfully realized.

All the modules were first designed and simulated for theoretical results using TracePro software, a ray tracing software which maps all the rays emitted from the LEDs and gives a illumination pattern on the observation screen.

These simulated results were then practically realized by actually constructing the modules and compared with the simulation results. The illumination patterns of the practical modules were obtained using ImageJ software.

The minimum intensity, maximum intensity, mean and standard deviation between the pixels were calculated and tabulated.

\section{Future Works}

The approach is to reduce the number of LEDs to very minimum value. The idea is to create a virtual source and thereby increasing the divergence from a single LED which creates a single light box. Therefore this can be achieved by light folding technique by placing small mirrors in front of the LED. By this we can illuminate a larger area with single LED.

\section{REFERENCES}

[1] "Designing light-emitting diode arrays for uniform near-field irradiance", Ivan Moreno, Maximino Avendano and rumen I. Tzonchev.

[2] "Bit Slice Addressing of LCD" T N Ruckmongathan

[3] "Imaging Via Backlights" Adrian Travis, Neil Emerton, tim Large, Liyin Chen and Steven Bathiche

[4] LCD Backlights by Shunsuke Kobayashi, Shigeo Mikoshiba and Sungkyoo Lim.

[5] Introduction to Driving LED Matrices, Application Note 1216

[6] Backlight Technology Overview -Brad Lizotte, 2005

\section{BIOGRAPHIES}

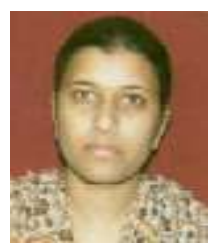

Shubha Kulkarni obtained her B.E and M.E from Karnataka University, M G R University during 1999 and 2007. Presently working as Assistant professor in the Department of Electrical and Electronics Engineering at Dayananda Sagar College of Engineering, Bangalore, India. Her interests are in the area of Power Electronics, power system Operation and control, Power Transmission and distributions system studies, FACTS Controllers.

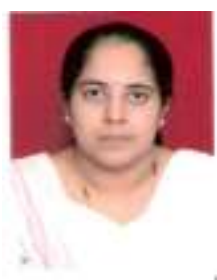

Ramamani V obtained her B.E from Visvesvaraya Technological University, Belgaum during 2003. Presently working as Assistant professor in the Department of Electrical and Electronics Engineering at Dayananda Sagar College of Engineering, Bangalore, India. Her interests are in the area of Power Transmission and distributions system studies, FACTS Controllers. ramya1981@hotmail.com

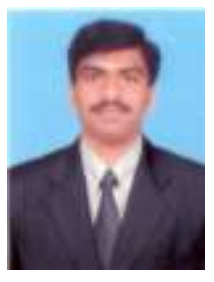

Manjunatha Babu P obtained his B.E and M.E from Visvesvaraya Technological University, Bangalore University during 2004 and 2010. Presently working as Assistant professor in the Department of Electrical and Electronics Engineering at BMS Institute of Technology \& Management, Bangalore, India. His interests are in the area of power system Operation and control, Power Transmission and distributions system studies, Power system Reliability, FACTS Controllers. 
Obtained his B.E in the year 1968, from

Coimbatore Institute of Technology

,Coimbatore. He has served for 7 years in

Hindustan Zinc Limited a mining \& metallurgical Industry as Senior Maintenance Engineer and at Mysore Paper mills Limited an Integrated Paper and Sugar Industry for 25 years in Electrical Maintenance, Training and Management Development and HR and presently serving as Assistant Professor in Dayananda Sagar College of Engineering .He is also associated with Quality Circle Forum of India as a trainer in quality circles. His special interests are people's involvement in quality improvements, maintenance prevention and Power System reliability.

rajaram.

krishnamurthi@gmail.com 